\title{
Discussion on Supply Chain Coordination of Apparel Industry from Perspective of the Secondary Ordering Method
}

\author{
Lili Liang, Lin Yan \\ Yantai Nanshan University, Yantai, 265706, China
}

Keywords: Secondary ordering, Apparel industry, Supply chain, Coordination

\begin{abstract}
Apparel products are actually products with short life cycle. They are characterized by rapid market demand with lathe change range, high marginal profit and inscrutability. Thus, they can be easily imitated in market competition, which will reduce competitive edge, reduce marginal profit and own strong product substitutability. Thus, apparel industry supply chain has long ordering cycle, which will influence product price over time and ordering problem of single retailers ordering from multiple manufacturers. This paper mainly analyzes and discusses supply chain coordination from the perspective of the secondary ordering method.
\end{abstract}

\section{Introduction}

As apparel industry continuously approaches people's daily life, apparel industry owns unremitting market requirement, so it is called an industry which will never decline and has wide application prospect. The Silk Road appeared in China 2000 years ago, so China as a world factory owns long export apparel history. In current stage, annual output of apparel in China can reach 10 billion, accounting for about $60 \%$ of global output. Hence, China belongs to a large country in apparel. However, as economic crisis happens continuously, the industry suffers great impacts. Thus, domestic apparel industry is in extreme misery. To cope with financial crisis, domestic apparel industry needs to reduce cost, to ensure manufacture in China and to improve overall quality under the precondition of production cost decrease. On this basis, it is very important to establish apparel enterprise supply chain which has accurate prediction, manages purchase, plans production and manages distribution.

\section{Overview of apparel products}

\section{Definition of apparel products}

Apparel products refer to intangible and tangible products offered by the market which fully meet market requirement and consumers' desire. In other words, the products not just need to meet actual demands of apparel entities which meet market consumers, including shell fabric, quality, function, style and modeling etc., but also own some services or brands which can bring consumers with psychological gratification and additional benefit. Generally, apparel commodities mainly include core commodities, form commodities, additional commodities and potential commodities etc.

\section{Features of apparel products}

\section{Functionality}

Apparel belongs to requisite in people's daily life. Firstly, apparel must conform to the functions of resisting chill and covering body. As living quality improves continuously, the requirements for apparel functions become higher and higher. People start to pay attention to healthcare function, protection function and sanitation function.

Popularity

Apparel popularity actually is apparel fashion. Apparel popularity owns certain rapid variability in terms of style design, color match and shell fabric style. Apparel popularity is characterized by transient, periodic, universal and permanent changes. 


\section{Innovation}

Due to transient life cycle, it is hard to accurately predict market demand of apparel. The products with high commercial profit own certain fashion and seasonality and can be easily imitated. This reduces competitive edge and marginal profit.

\section{Seasonality}

Apparel products have certain seasonal characteristic. The changes in four seasons will influence dressing. In summer, people wear less, and in winter, people wear heavily. Different season have different characteristics.

\section{Spirituality}

Apparel can rationally reflect inward world to some extent. Different people pursue different dressing. According to personal characters, people will wear the clothes with different brands, grades and appearances.

\section{Overview of supply chain}

Supply chain management means various enterprises share resources, cooperate sincerely and optimize resource efficiency allocation so as to improve overall effect of supply chain. In actual operation, enterprises on the supply chain own different market influence and different supply chain profit segmentation proportion ${ }^{[1]}$.

\section{Discussion on supply chain coordination of apparel enterprises from the perspective of the secondary ordering method}

Due to the development of market competition and progress of science and technology, apparel products update quickly and product cycle is shortened. Apparel products own large fluctuant demand and timeliness, and have nonlinear relationship with external environment. For retailers, they need to analyze manufacturers' ordering cost and ordering quantity, and rationally analyze whether the secondary ordering strategy is better than the primary ordering strategy based on manufacturers' primary production mode according to manufacturers' production capacity and wholesale price.

\section{Problem description}

Manufacturers trade with one retailer. The products manufactured by manufacturers are irreplaceable, and they can only utilize downstream retailer market for sales. Retailers establish ordering strategy and they are faced with a problem that whether the secondary ordering method can gain more profits than primary ordering method.

$\mathrm{T}$ is ordering cycle. The wholesale price of manufacturer $\mathrm{i}$ is $\mathrm{w}_{\mathrm{i}}$. Production capacity is a constant $\mathrm{g}_{\mathrm{i}}$. The retail price of unit product is $\mathrm{p}$. Every ordering cost is $\mathrm{Ci}$, with small proportion of total cost and ordering cost. After market's actual norm is reached at the end of the period, if it does not comply with market, retail cost which fails to meet demand is expressed as e. If there are products which are not sold, the products which are not sold are treated at the price of $\mathrm{v}$. Customers' actual demand is random variable $\mathrm{D}$; distribution function is $\mathrm{F}(\mathrm{x})$; probability function is $\mathrm{f}(\mathrm{x})$. a product retailer with $1 / \lambda$ randomly obeys expectation index distribution. Based on multiple manufacturers, not totally same wholesale price, ordering quantity and market demand exist. It is necessary to rationally use two or more ordering forms.

\section{Modeling}

\section{Profit under primary ordering mode}

Hypothesis $0, \mathrm{v}<\mathrm{w}_{1} \leqslant \mathrm{w}_{2} \leqslant \ldots \ldots . \mathrm{w}_{\mathrm{n}} \leqslant \mathrm{p}$

Hypothesis 1 , at least one group $(i, j)$ can meet $w i \neq w j, i \leq n, \quad 1 \leq i$

Hypothesis 2, the minimum wholesale price is needed when retailers choose manufacturers in order to own higher profits.

Hypothesis 3, gi $<$ F-1 (wi) 
Manufacturers are ranked according to actual wholesale price. Multiple manufacturers have different wholesale prices. Based on analyzing the above hypotheses, it is found that generally, retailers will contact manufacturers with advantages of certain production capacity and wholesale price. When retailers' actual order cannot be fully met, retailers will fully order from the first $\mathrm{m}-1$ manufacturers, i.e. Qi=gi. Retailers will not order goods without limit. For the mth manufacturer, retailers will not fully order according to actual conditions. Based on market development demand, it is just necessary to order according to market demand[2].

In market requirement of random D, retailers' profit expectation function:

$$
E\left(\pi_{R 1}\right)=-(p+e-v) \int_{0}^{\rho^{*}} F(x) d x+(p+e) Q^{*}-\sum_{i=1}^{m} w_{i} Q_{i}^{*}-e \lambda-\sum_{i=1}^{m} C_{i}
$$

\section{Profit under secondary ordering mode}

The secondary ordering strategy means when the ordering cycle starts, manufacturers give quoted price to retailers according to corresponding wholesale price. Retailers need to analyze actual ordering quantity in accordance with market demand and wholesale price. In the process of approaching the end of ordering cycle, manufacturers carry out secondary offer according to market demand and production situation. Compared with the first offer, this offer is different and can gain more accurate and the latest offer market information, and the ordering quantity can be adjusted. If the first ordering cannot meet actual demand, goods should be supplemented according to the second price.

Hypothesis 4, at the starting time $\mathrm{t}$, wholesale price of each manufacturer is $\mathrm{w}_{\mathrm{i}}^{\prime}$; the offer at $\mathrm{T}$ is wi;

Hypothesis 5, at $\mathrm{t}$, the retailer orders goods Qi from manufacturers; at T, ordering quantity $\Delta$ Qi is adjusted; the final ordering quantity is $\mathrm{Qi}^{\prime \prime}$.

For analysis convenience, we assume wholesale price at the first ordering time $\mathrm{T}$ is same with manufacture's wholesale price at T. It is found from analysis of the above hypotheses that, in the secondary ordering process, the retailer adjusts ordering quantity, which will reduce expected profit and especially adjust retailer's ordering quantity by a large margin, i.e. own large $\Delta$ Qi. Expected profit will be greatly promoted. Besides, small proportion of ordering cost will be occupied when the retailer orders goods every time. However, since there are multiple manufacturers, whenever ordering boosts, ordering cost will make the trailer suffer certain loss. Based on N manufacturers, the secondary ordering has certain advantages for manufacturers, but the retailer will be affected.

\section{Apparel supply chain income sharing coordination based on secondary ordering strategy}

Hypothesis 6, based on mobile phone sharing, expected apparel supply chain profit can be properly divided into $\mathrm{m}$ profit chains $\mathrm{M}_{\mathrm{i}}$;

Hypothesis 7, every expectation chain head includes the expectation gained by the retailer from product sales after the goods are ordered from the manufacturer, such as expected profit $\mathrm{E}$ gained according to $\mathrm{E}$ and manufacturer.

The primary ordering price of the retailer is $\mathrm{w}_{1}$; the secondary ordering price of the retailer is $\mathrm{w}_{2}$; production costs of the manufacturer are $\mathrm{C}_{1}$ and $\mathrm{C}_{2}$. It is necessary to share the profit in product sale. The sharing proportion is (1- $\phi \mathrm{i})$. Sharing income coordination profit is $\left\{\mathrm{w}_{1}, \mathrm{w}_{2}, \phi \mathrm{i}\right\}$. The expected profit gained through the market is:

$$
\begin{aligned}
E\left(\pi_{M A i}\left(Q_{d i}\right)\right)= & \int_{0}^{Q_{x}} p x f(x) d x+\int_{0}^{Q_{d x}} v\left(Q_{d i}-x\right) f(x) d x \\
& +\int_{Q_{d i}}^{+\infty} p x f(x) d x-\int_{Q_{d i}}^{+\infty} b\left(x-Q_{d i}\right) f(x) d x \\
= & {[p-b] \lambda+b Q_{d i}-(b-v) \int_{0}^{Q_{d i}} F(x) d x }
\end{aligned}
$$

At this time, the profit is not all profit of profit chain. Since it is shared profit, the retailer will share profit with the manufacturer according to certain proportion ${ }^{[3]}$. 


\section{Adjust retailer's profit}

In accordance with relevant agreement between the manufacturer and the retailer, the retailer will share some profit with manufacturer. Thus, when the retailer orders goods and sell, certain sale profit will be reserved for the manufacturer. The final profit is:

$$
\begin{aligned}
E\left(\pi_{M R i}\left(Q_{d i}\right)\right)= & \int_{0}^{Q_{d}} \phi_{i}\left[p x+v\left(Q_{d i}-x\right)\right] f(x) d x-w_{i 1} Q_{d i} \\
& +\int_{Q_{d}}^{+\infty} \phi_{i}\left[p x-b\left(x-Q_{d i}\right)\right] f(x) d x-\int_{Q_{d i}}^{+\infty} w_{i 2}\left(x-Q_{d i}\right) f(x) d x \\
& =\left(\phi_{i} p-w_{i 2}-\phi_{i} b\right) \lambda+\left(w_{i 2}+\phi_{i} b-w_{i 1}\right) Q_{d i}-\left(w_{i 2}+\phi_{i} b-\phi_{i} v\right) \int_{0}^{Q_{d i}} F(x) d x
\end{aligned}
$$

We can find that when disperse policy decision is applied, the retailer's optimal ordering quantity will decline with the price of retailer's product wholesale continuously rises in the first stage (cheap form); in the second stage (expensive form), as product wholesale price rises, the retailer's optimal ordering quantity will rise. As profit sharing proportion of retailer is on the rise, the optimal ordering quantity of the first time will decline properly.

Adjust profit of income sharing manufacturer

According to actual ordering quantity and ordering times of retailer, the manufacturer needs to rationally arrange production plan and will not produce until receiving the retailer's order.

Firstly, prior to normal sale, the retailer's ordering quantity is $\mathrm{Q}_{\mathrm{d}}$. The actual production quantity of manufacturer is $(1+\alpha) \mathrm{Q}_{\mathrm{d}}$. Due to $0 \leqslant \alpha$, the manufacturer will produce more goods $\alpha \mathrm{Q}_{\mathrm{d}}$. They will sell them when the retailer supplements goods. The profit gained by the manufacturer is

$$
E\left(\pi_{M s i}\left(Q_{d i}, \alpha\right)\right)=\int_{0}^{Q_{w i}}\left\{\left(1-\phi_{i}\right)\left[p x+v\left(Q_{d i}-x\right)\right]+w_{i 1} Q_{d i}-c_{i 1}(1+\alpha) Q_{d i}+v \alpha Q_{d i}\right\} f(x) d x ;
$$

Secondly, after sale is completed, if $\mathrm{Q}_{\mathrm{d}} \geqslant \mathrm{x}$, the manufacturer will handle surplus finished products according to the value of unit product. If $(1+\alpha) Q_{d} \geqslant x>Q_{d}$, when product sale ends, the retailer will propose to supplement goods to the manufacturer. However, since it belongs to the first production of flexible quantity, actual inventory of the manufacturer can comply with sale demand of the retailer. Thus, the secondary production is not needed. The profit is expressed as:

$$
\begin{aligned}
E\left(\pi_{M s i}\left(Q_{d i}, \alpha\right)\right)= & \int_{Q_{i}}^{(1+\alpha) Q_{d}}\left\{\left(1-\phi_{i}\right)\left[p x-b\left(x-Q_{d i}\right)\right]+w_{i 1} Q_{d i}\right\} f(x) d x \\
& +\int_{Q_{i}}^{(1+\alpha) Q_{d i}}\left\{w_{i 2}\left(x-Q_{d i}\right)-c_{i 1}(1+\alpha) Q_{d i}+v\left[(1+\alpha) Q_{d i}-x\right]\right\} f(x) d x
\end{aligned}
$$

It is found that, when disperse policy decision is applied in supply chain, the retailer's optimal ordering quantity will rise as the wholesale price increases in the first stage (cheap form). In the second stage (expensive form), the retailer's optimal ordering quantity will decline as the wholesale price increases. As manufacturer's reserved profit is on the rise, manufacturer's output will properly reduce in the first stage. Under the precondition where product wholesale price and income sharing coefficient influence the minimum ordering, manufacturer's output will be influenced in the first stage. The manufacturer rationally adjusts wholesale price and income coefficient in order to find out the cooperative retailer and rationally choose the optimal ordering quantity ${ }^{[4]}$.

\section{Simulation analysis}

We assume an apparel product owns $\lambda=200$ random demand expectation distribution index, and the nationwide uniform price is $p=1000$. By use of multiple manufacturers offering goods source for the retailer and the secondary ordering strategy (i.e. before seasonal sale ends and seasonal sale starts, the manufacturer rationally applies expensive production and cheap production), the manufacturer uses the wholesale price of low production cost and offers corresponding goods source in order to effectively coordinate supply chain. After the retailer gains goods, the retailer sells goods to the market to gain profit. According to corresponding distribution coefficient and sharing profit, we assume the cost of manufacturer in the two stages are $\mathrm{C} 1=100$ and $\mathrm{C} 2=250$. the wholesale prices are 
$\mathrm{w}_{1}, \mathrm{w}_{2}, \mathrm{w}_{1}<\mathrm{c}_{1}, \mathrm{w}_{2}<\mathrm{c}_{2}, \mathrm{w}_{1}<\mathrm{w}_{2}$. We assume the residual value $\mathrm{v}$ is 90 ; shortage cost $\mathrm{e}$ is 750 ; delayed supply cost $\mathrm{b}$ is 80 , and $\Delta E=\left\{\left[E^{*}(\pi)-E(\pi)\right] / E(\pi)\right\}$ means the percentage of growth profit.

For the retailer, sharing income coordination strategy is shown in the following table:

Table 1. Sharing income coordination strategy

\begin{tabular}{ccccccc}
\hline$\dot{\phi}_{i}$ & $w_{i 1}^{*}$ & $Q^{*}{ }^{*}$ & $\alpha_{\mathrm{di}}{ }^{*}$ & $E\left(\pi_{R 2}\right)$ & $E^{*}\left(\pi_{R 2}\right)$ & $\Delta E$ \\
\hline 0.6 & 60 & 61 & 0.18 & 2972.5 & 3307.2 & $11.2 \%$ \\
0.65 & 65 & 53 & 0.69 & 2818.6 & 3212.3 & $13.9 \%$ \\
0.67 & 67 & 46 & 0.81 & 2794.1 & 3165.4 & $13.3 \%$ \\
0.68 & 68 & 40 & 0.99 & 2604.3 & 3070.9 & $17.9 \%$ \\
0.7 & 70 & 35 & 1.27 & 2496.7 & 2834.7 & $13.5 \%$ \\
\hline
\end{tabular}

It is found that higher sharing coefficient owns higher wholesale price and will reduce the retailer's optimal ordering quantity. Thus, manufacturer's flexible production coefficient boosts, and retailer's profit declines. After sharing income strategy coordination mode is applied, retailer's profit is higher than that when coordination strategy is not applied. In other words, sharing income strategy coordination mode can facilitate retailer's profit to some extent. If retailer's profit is low, retailer's ordering quantity in the first time will reduce ${ }^{[5]}$.

\section{Conclusions}

In one word, when supply chain coordination of apparel enterprises is analyzed based on the secondary ordering, it is necessary to rationally confirm income value range to ensure optimal profit and effectively improve overall profit of apparel enterprises. This paper offers certain reference for development of apparel industry.

\section{References}

[1] Tang Qi, Dong Hongyu, Study on supply chain inventory management performance evaluation of apparel enterprises. Journal of Southeast University (Philosophy and Social Science), 2014,16(z1):81-84.

[2] Feng Dongsheng, Study on application of commercial intelligence technology in apparel enterprise supply chain. Value Engineering, 2010,29(26):40-41.

[3] Zeng Mingang, Zhou Yanting, Quick reaction capability evaluation model of apparel enterprises based on supply chain. Collected papers of the 11th academic annual conference of Chinese Journal of Management Science, 2010:420-424.

[4] Lin Hanmi, Establish virtual enterprises and create agile supply chain - understand research report on supply chain reengineering of Hangzhou apparel trading enterprises in e-commerce times. Science and Technology Information (Education of Science and Technology), 2011(9):100-101.

[5] Zhu Fangyuan, Comparative study on supply chain of Chinese and foreign sports apparel enterprises - case study of Nike and Li-Ning. Market Modernization, 2010(32):67-69. 